\title{
ANALISIS PERBANDINGAN TRIBOMETER TYPES DENGAN VARIASI MATERIAL - REVIEW
}

\author{
Adzan Ramadhan \\ Jurusan Teknik Mesin, Fakultas Teknik, Universitas Brawijaya ; Jl. Mayjend. Haryono No. 167, \\ Malang,65145, Indonesia \\ Telp. : +62-341-552491; Fax : +62-341-552491 \\ Adzanejane@gmail.com
}

\begin{abstract}
There are many tribometers especially friction test to make a research and to develop many kind of materials. Three types of tribometer that common to use for friction test are thrustwasher, block on ring, and pin on disk. In this study, Alumunium and Steel ST 40 was used to investigate the wearness value. The load used in the pin is $24,81 \mathrm{~kg} / \mathrm{mm}^{2}$. The result showed that Aluminium have higher wearness value than Steel ST 40.
\end{abstract}

Keywords: tribometer, thrustwasher, block on ring, pin on disk, aluminium, steel ST 40

\section{Pendahuluan}

Tribometer adalah suatu instrument yang mengukur jumlah tribological, Koefisien dari gesekan, kekuatan gesekan dan volume keausan, antara dua permukaan kontak. Hal ini ditemukan oleh ilmuan Belanda abad ke-18 Musschenbroek. Tribometer adalah nama umum yang diberikan kepada mesin atau alat yang digunakan untuk melakukan tes dan semulasi keausan, gesekan dan pelumasan pada studi tribology. Tribometer sering sangat spesifik dalam fungsi mereka dan direkayasa oleh produsen yang menginginkan untuk menguji dan menganalisa kinerja jangka panjang produk mereka. Contohnya adalah manufaktur ortopedi implan yang telah menghabiskan sejumlah besar uang untuk mengembangkan tribotester yang akurat memproduksi gerakan dan kekuatan yang terjadi pada manusia.[1]

Tribometer sederhana dijelaskan oleh gantungan massa dan massa bertumpu pada permukaan horizontal, terhubung satu sama lain melalui string dan katrol. Koefisien dari gesekan $\mu$, ketika system stasioner, ditentukan oleh peningkatan masssa meenggantung sampai pada akhirnya massa terseubut mulai meluncur. Kemudia menggunakan persamaan umum untuk gesekan

$$
F=\mu N
$$

Dimana $\mathrm{N}$ adalah gaya normal, sama dengan berat (massa $x$ gravitasi) kedudukan massa $\left(m_{\mathrm{T}}\right)$ dan $\mathrm{F}$ gaya angkat, sama dengan berat (massa $x$ gravitasi) massa menggantung $\left(m_{H}\right)$.

$$
\mu=m \mathcal{H} / m \mathcal{T}
$$

Untuk menentukan koefisien kinetic dari gesekan massa menggantung yang meningkat atau menurun sampai system massa bergerak pada kecepatan konstan. Dalam kedua kasus, Koefisien gesekan disederhanakan pada rasio kedua massa Dalam kebanyakan aplikasi pengetesan yang menggunakan tribometer, diukur dengan membandingkan massa atau permukaan spesimen tes sebelum dan setelah pengujian. Peralatan dan metode yang digunakan untuk meneliti permukaan dipakai termasuk optik mikroskop, mikroskop elektron scanning, interferometry optik dan mekanik kekasaran penguji.Untuk itu diperlukan kajian yang membahas tentang kelebihan dan kekurangan serta perbandingan dengan material yang biasa kita temui dipasaran

\section{Metodologi Penilitian}

A. Metode Pengambilan Data

Dalam penelitian ini digunakan dua metode dalam pengumpulan data. Adapun metode penelitian yang digunakan ini adalah Metode Penelitian Kepustakaan (Library Research). Metode ini digunakan dalam mendapatkan data dengan caraobservasi 
dengan literatur yang digunakan. Kemudian juga dengan membaca sumber-sumber data informasi lainnya yang berhubungan dengan pembahasan. Sehingga dengan penelitian kepustakaan ini diperoleh secara teori mengenai permasalahan yang dibahas.

\section{B. Kerangka Pemikiran}

\section{Thrust Washer}

Instrumen ini cocok untuk beberapa standar ASTM serta berbagai percobaan kustom. la juga memiliki sejarah panjang digunakan untuk membuat patokan suatu bahan untuk berbagai perusahaan dan industri dengan kekayaan aplikasi eksperimental praktis. thrustwasher dapat melakukan berbagai kondisi eksperimental, termasuk 10 untuk $1.000 \mathrm{~N}$ beban normal dan 25-4200 RPM kecepatan rotasi geser. Desain kustom di Lehigh saat ini memungkinkan untuk fleksibilitas tambahan, termasuk peningkatan rentang beban, variasi kecepatan, strategi pelumasan bervariasi dan pengendalian lingkungan karena skema konstruksi modular. Instrumen ini mampu digunakan untuk suhu di atas $200{ }^{\circ} \mathrm{C}(400 \stackrel{\circ}{\circ})$. Kontak geometri meliputi tipikal pertemuan konsentris washer sebaik geometris flat on flat [2]

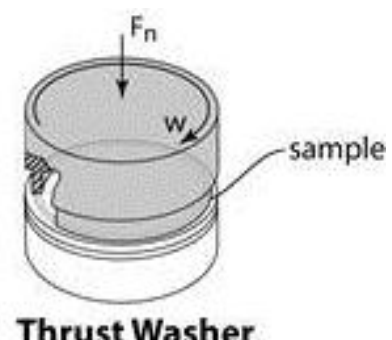

Gambar 1. Thrust Washer Tribometer

Washer:

Kemampuan Elemen Pengujian Thrust

- Cocok untuk berbagai jenis standar ASTM dan percobaan kustom.

- Digunakan untuk mem-benchmark (patokan ) suatu material.

- $10-1000 \mathrm{~N}$ beban yang dapat diterima

- 25-4200 rpm kecepatan rotasi geser

- Suhu $>200 \stackrel{\circ}{\circ}$

2. Pin on Disc

Pin on disc tribometer terdiri dari stasioner "pin" di bawah beban yang diterapkan dengan sebuah disk yang berputar. Pin dapat berbentuk apapun untuk mensimulasikan kontak tertentu, tetapi bentuk bulat sering digunakan untuk menyederhanakan geometri kontak. Koefisien dari gesekan ditentukan oleh rasio kekuatan gesekan untuk pemuatan gaya pada pin. Pin on disc tes telah terbukti bermanfaat dalam menyediakan tes keausan sederhana dan gesekan tes untuk pelapis gesekan rendah seperti karbon berlian-seperti lapisan pada katup keretadan pada komponen mesin pembakaran internal.

Pengujian pin-on-Disk adalah metode karakteristik koefisien gesekan, gaya gesekan, dan tingkat keausan antara dua bahan. Beberapa konfigurasi yang tersedia tergantung pada tujuan dan sasaran. spesifikasi umum meliputi: ASTM G99, ASTM G133 dan ASTM F732. Pengujian pin-on-disk dapat mensimulasikan beberapa mode pakaian, termasuk: searah, dua arah, omnidirectional, dan quasi-rotasi. Evaluasi massa-kerugian dan analisis diferensial cairan tes biasanya dilakukan post-test untuk mengkarakterisasi sifat pakai. Selain itu, profilometer kontak dapat dimanfaatkan untuk mengevaluasi perubahan topografi permukaan karena artikulasi. evaluasi metalurgi dari post-test pakai jaringan parut juga dapat dilakukan. Pengujian juga dapat memperkenalkan puingpuing ketiga bagian untuk evaluasi dipercepat.

Elemen untuk melakukan pengujian pinon-disk memakai sesuai dengan ASTM G99, ASTM G133 dan ASTM F732, 12-stasiun frame uji keausan. unik, mesin berkapasitas tinggi ini memungkinkan untuk pengujian beberapa kombinasi material pada suatu waktu, pada bingkai tes tunggal. Pengaturan 12-stasiun juga memungkinkan untuk kepercayaan statistik tambahan dengan menguji beberapa sampel per kondisi.[3]

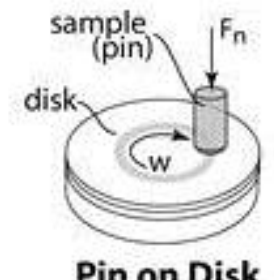

Gambar 2. Pin on Disk Tribometer 

disk:

Kemampuan elemen pengujian pin-on-

- $1000 \mathrm{~N}$ beban normal per stasiun

- $100+\mathrm{MPa}$ stres kontak

- $2,5 \mathrm{~N}-\mathrm{m}$ torsi

- Sampai dengan 0,25 km per menit gerak searah

- 12 individu, suhu dikontrol cekungan tes untuk simulasi

- 4 suhu dikontrol beban-rendam cairan basins gain

- Kecepatan geser $<15 \mathrm{~mm} / \mathrm{s}$ to $1,000 \mathrm{~mm} / \mathrm{s}$

- Suhu $>200^{\circ} \mathrm{C}$

Analisis bagian keausan ketiga: Elemen memiliki kemampuan untuk melakukan analisis memakai tubuh ketiga sebagai bagian dari proyek pin-on-disk. Dengan memperkenalkan partikulat tubuh ketiga dalam artikulasi tes, simulasi akurat dari kondisi tertentu dapat dibuat (misalnya semen tulang di ruang sendi).

Analisis Keausan Goresan-Permukaan: Tes ini juga dapat dilakukan dengan memperkenalkan jaringan awal rekayasa pada disk sebelum pengujian pin-on-disk. aplikasi tertentu ini biasanya digunakan untuk mensimulasikan efek dari kompleks, memakai berkepanjangan ketika mengevaluasi serta pelapisan logam. Pasca-Test Analisis Metalurgi: Setelah kesimpulan dari pengujian, kedua pin dan disk dapat dievaluasi metallurgically menggunakan stereoscope atau pembesaran tinggi pemindaian mikroskop elektron (SEM). Hal ini memungkinkan untuk lebih memahami kondisi permukaan yang mungkin terjadi[4]

\section{Block on Ring}

Tes yang menggunakan block terhadap sebuah cincin tes yang berputar pada kecepatan tertentu untuk nomor revolusi tertentu.Volume Block scar dan ring scar dihitung setelah tes menggunakan profilometer terpadu. gaya gesekan terus-menerus diukur selama tes dengan sel beban. data ini, dikombinasikan dengan data gaya normal, dikonversi ke nilai-nilai koefisien dari gesekan lalu dilaporkan.[5]

Blok-on-Ring Tribometer mampu mensimulasikan berbagai kondisi dilapangan yang sulit, misalnya suhu tinggi, kecepatan tinggi dan tekanan beban tinggi. Koefisien gesek dihitung in-situ dengan mengakuisisi gaya geser didasarkan pada torsi momentum tuas. Karakteristik memakai bahan dapat ditentukan setelah pengujian. Tribometer ini digunakan untuk pengujian pelapis, gemuk, aditif dan geser kinerja. Hal ini sangat fleksibel dalam memungkinkan pilihan yang berbeda yang akan digunakan, misalnya, untuk geometri kontak, yaitu titik, garis, dan area di cincin. Suhu mengontrol Kontrol suhu dapat dikelola melalui pemilihan operator ruang dan pemanas konfigurasi, mengatur lingkungan atau uji suhu benda. Dikendalikan komputer sistem memungkinkan kontrol diprogram titik suhunya, siklus parameter uji, dan urutan pengujian awal. suhu sampel dapat dicapai hingga $750 \circ \mathrm{C}$ dengan pendingin eksternal. Selain itu, peningkatan suhu akibat proses geser dapat diukur sebagai termokopel dapat dimasukkan ke bagian belakang sampel sangat dekat dengan bidang kontak. Parameter beban: 1-150 N Rotasi: hingga 1500 rpm Ø-Ring: hingga 40 mm Suhu: hingga $750^{\circ} \mathrm{C}$ Khas Standard Metode ASTM G 77, metode uji standar untuk peringkat ketahanan bahan untuk memakai geser menggunakan pengujian block on ring

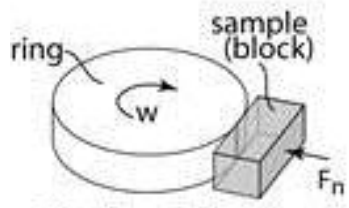

$$
\text { Block on Ring }
$$

\section{Gambar 3. Block on Ring Tribometer}

Kemampuan uji elemen block on ring :

- Biasa digunakan untuk bushing dan bearing

- 5-1000 N kemampuan beban yang dapat diterima

- kecepatan geser $<15 \mathrm{~mm} / \mathrm{s}$ to $>1,000$ $\mathrm{mm} / \mathrm{s}$ kecepatan geser

- Suhu mencapai $750 \stackrel{\circ}{\circ}$

4. Variasi Material

Pada komparasi dan pengujian kali ini dipilih material yang banyak terdapat dan sering digunakan di pasaran yakni alumunium dan baja ST 40. 
C. Tabel-tabel.

Tabel 1. Perbandingan antara Ketiga

Tribometer

\begin{tabular}{|c|c|c|}
\hline $\begin{array}{c}\text { Jenis } \\
\text { Tribometer }\end{array}$ & Kelebihan & Kekurangan \\
\hline $\begin{array}{l}\text { Thrust } \\
\text { Washer }\end{array}$ & $\begin{array}{l}\text {-dijadikan } \\
\text { benchmark } \\
\text { tiap material } \\
\text {-cocok untuk } \\
\text { beberapa } \\
\text { standar ASTM } \\
\end{array}$ & $\begin{array}{l}\text {-kecepatan } \\
\text { rotasi geser } \\
\text { relative } \\
\text { rendah }\end{array}$ \\
\hline Pin on Disk & $\begin{array}{l}\text {-banyak } \\
\text { digunakan di } \\
\text { berbagai } \\
\text { research } \\
\text {-rentang } \\
\text { beban cukup } \\
\text { lebar } 1 \text { to } \\
1,000 \mathrm{~N} \\
\text {-Dapat } \\
\text { mensimulasiha } \\
\text { I kompleks dan } \\
\text { berkepanjanga } \\
\mathrm{n} \\
\end{array}$ & $\begin{array}{l}- \text {-Terjadi } \\
\text { goresan akibat } \\
\text { pinggiran dari } \\
\text { pin dan } \\
\text { mempengaruhi } \\
\text { kondisi sliding }\end{array}$ \\
\hline $\begin{array}{c}\text { Block on } \\
\text { Ring }\end{array}$ & $\begin{array}{l}\text {-digunakan } \\
\text { untuk uji } \\
\text { standar } \\
\text { peningkatan } \\
\text { ketahanan } \\
\text { standar } \\
\text { - penting untuk } \\
\text { industri bahan } \\
\text { dan penelitian } \\
\text { - Suhu tinggi } \\
\text { mencapai } 750 \\
{ }^{\circ} \mathrm{C}\end{array}$ & $\begin{array}{l}\text {-Terjadi } \\
\text { goresan akibat } \\
\text { pinggiran dari } \\
\text { pin dan } \\
\text { mempengaruhi } \\
\text { kondisi sliding }\end{array}$ \\
\hline
\end{tabular}

Tabel 2. Perbandingan antara Alumunium dengan Baja ST.40

\begin{tabular}{|c|c|c|}
\hline Jenis Material & Kelebihan & Kekurangan \\
\hline Alumunium & $\begin{array}{l}\text {-Tahan karat } \\
\text {-Ekonomis } \\
\text {-Bobot ringan }\end{array}$ & $\begin{array}{l}\text {-Kekuatan } \\
\text { kurang } \\
\text {-Lemah } \\
\text { terhadap } \\
\text { benturan }\end{array}$ \\
\hline Baja ST.40 & $\begin{array}{l}\text {-Kekuatan } \\
\text { tinggi } \\
\text {-Hampir tidak } \\
\text { memiliki } \\
\text { perbedaan } \\
\text { nilai muai } \\
\text { dan susut }\end{array}$ & $\begin{array}{l}\text {-Bisa berkarat } \\
\text {-Tidak } \\
\text { fleksibel } \\
\text {-Lemah } \\
\text { terhadap gaya } \\
\text { tekan }\end{array}$ \\
\hline
\end{tabular}

D. Flowchart Penelitian

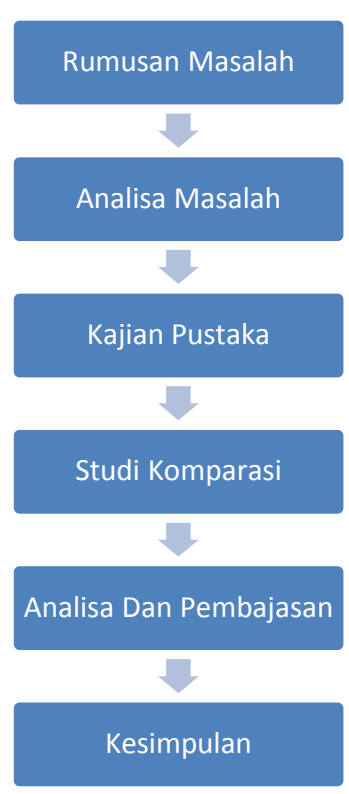

\section{HASIL DAN PEMBAHASAN}

Pada pengujian yang dilakukan pada ketiga alat relatif sama dan pada bahan material Aluminium sebelum di uji mempunyai kekerasan rata-rata permukaan disc: 0,25 $\mu \mathrm{m}$, jarak pin dengan beban: $165 \mathrm{~mm}$, berat pin sebelum pengujian: $3,98 \mathrm{~g}$ dan tekanan pada pin: $24,81 \mathrm{~kg} / \mathrm{mm}^{2}$. Pengujian pada salah satu alat dengan bahan material pin Aluminium.

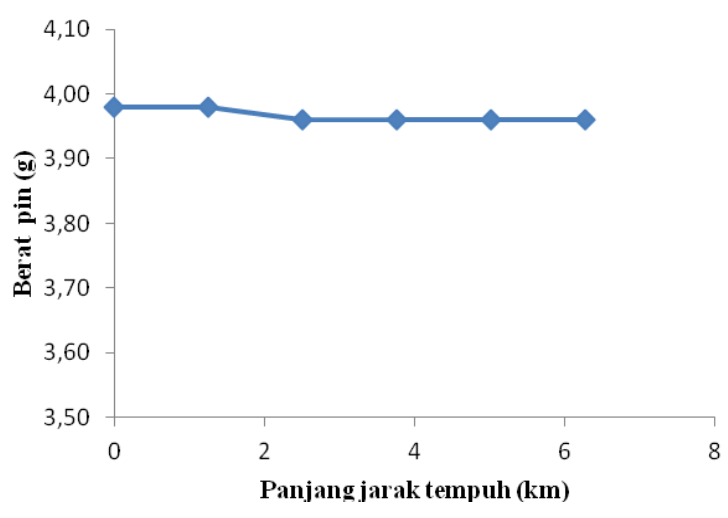

Gambar 4. penurunan berat pin alumunium pada pengujian,

Pada pengujian terjadi penurunan yang relatif besar $(0,02 \mathrm{~g})$ untuk pengujian pertama. Sedangkan pada pengujian kedua sampai ke lima tidak ada penurunan berat pin, hal ini 
dikarenakan bahan yang digunakan adalah aluminium yang mempunyai sifat ulet sehingga terjadi penempelan material pada pin ke disc.[6]

Selanjutnya ialah hasil pengujian keausan baja ST.40 menggunakan salah satu alat tribometer yang dilakukan di lab teknik kampus Unwahas, dengan putaran disc diatur 190 $\mathrm{rpm}$, dan penekanan pada pin $38,38 \mathrm{~kg} / \mathrm{mm} 2$.

Hasil pengujian keausan baja ST.40 menggunakan salah satu alat tribometer diperoleh hasil sebagai berikut ini :

1. Kekasaran rata-rata permukaan disc sebelum pengujian: $2,17 \mu \mathrm{m}$

2. Temperatur pin saat pengujian: $32^{\circ} \mathrm{C}$

3. Berat pin sebelum pengujian : 10,36 g

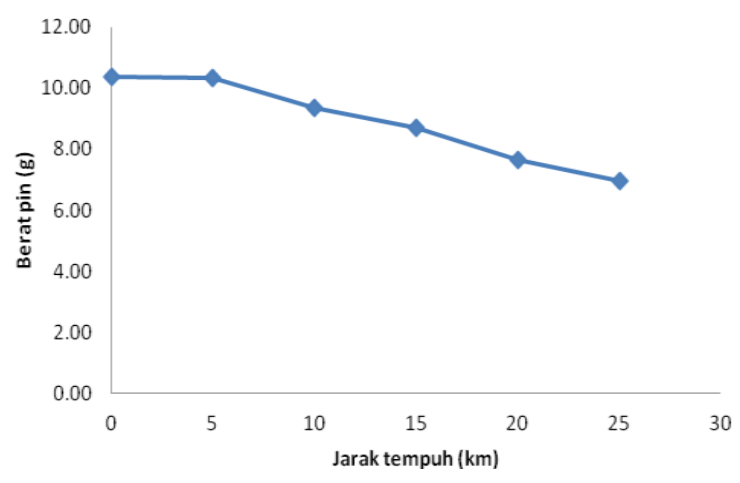

Gambar 5.Penurunan berat pin pada pengujian Baja ST 40

Karena perbedaan penekanan pada pengujian kali ini sehingga terlihat baja seperti memiliki keausan yang dengan jarak tempuh yang relative rendah jika dibandingkan dengan alumunium namun jika penekanan pada pin di samakan dan kecepatan putaran disc sama maka hasil akan menunjukan bahwa tingkat keausan baja relative lebih rendah dibandingkan dengan alumunium. Selain itu factor lain yang dapat mempengaruhi dalam konteks pengujian ini ialah factor kekasaran kedua material yang tidak diketahui sehingga dapat menciptakan variable yang berbeda jika nilai kekasarannya tidak diketahui.[7]

\section{KESIMPULAN}

Dari hasil penelitian dapat disimpulkan sebagai bahwa faktor koefisien gesek terbesar dalam penelitian yang dilakukan terjadi pada pengujian Alumunium sebesar 10,477 m3/N.m.
Pada pengujian pin dengan material Baja ST.40 didapatkan penurunan berat pin yang besar pada pengujian sebesar 3,74 . Faktor koefisien gesek yang besar terdapat pada pengujian sebesar 26,9-10,4 mm3/N.m

Sehingga dapat disimpulkan bahwa baja memiliki koefisien gesek yang terlihat lebih besar dikarenakan nilai penekanan yang berbeda, pada Alumunium penekanan pada pin sebesar: $24,81 \mathrm{~kg} / \mathrm{mm}^{2}$ sedangkan pada Baja ST.40 sebesar $38,38 \mathrm{~kg} / \mathrm{mm}^{2}$.

\section{DAFTAR PUSTAKA}

[1] https://en.wikipedia.org/wiki/Tribometer

[2] http://www.lehigh.edu/ intribos/facilities.ht $\mathrm{ml}$

[3] Bezzazi M, Khamlichi A., Jabbouri A, Reis P, Davim JP (2007). Experimental characterization of Frictional behaviour of Clutch Facings using Pin-on-disk machine. Materials and Design. Elsevier Sci. Netherlands. 28(7): 2148-2153.

[4] Hoglund,E.,1984. "Elastohydrodynamic Lubrication;Interferometric Measurements, Lubricant Rheology and Subsurface Stresses, Doctoral Thesis, Luleh University of Technology, Sweden, 32D,

[5] Dowson, D. History of Tribology, Second edition, London: Professional Engineering Publishing, 1998.

[6] Darmanto, Muhamad Thufik R. 2013 Analisis Keausan Alumunium Menggunakan Tribotester dengan Variasi Pelumas,Universitas Wahid Hasyim ,Semarang

[7] Anang Rohadi, Imam Syafaat, 2012 Analisis Keausan Baja ST.40 Menggunakan Tribotester dengan Variasi Pelumas,Universitas Wahid Hasyim ,Semarang 